\title{
Development and characterization of bamboo fiber reinforced biopolymer films
}

\begin{abstract}
A paradigm shift from petrochemical based packaging films for food packaging due to its non-renewable and waste disposal challenges has motivated research interest in development and characterization of biopolymer films. In this study, biocomposite films was prepared using bamboo fiber to reinforce modified and unmodified red seaweed SW Kappaphycus alvarezii, resulting in improved mechanical characteristics of $109.1 \mathrm{MPa}$ tensile strength, 55.4 MPa Young's Modulus and 22.3\% stretchability prior to breakage at the optimum value of $15 \%$ bamboo fibers loadings for unmodified biocomposite. There was general improvement in the fiber/matrix interface of the modified SW based composite films over the biopolymer films from unmodified SW bamboo reinforced films resulting in improved water vapour barrier as the fiber load increases up to Water vapour permeability value of 5.2 $(\mathrm{g} / \mathrm{s} / \mathrm{m} 2 / \mathrm{Pa})$., while the contact angle as high as $91^{\circ}$ was obtained. FTIR analysis validates the effective interaction of both the bamboo fibers and the seaweed matrix without any significant biochemical alteration of the seaweed within the frameworks of composite films. SEM characterization and contact angle measurement indicate that heterogeneous surface modification of the biopolymer film increases with the fiber loading. Results demonstrated the potential use of the renewable and biodegradable biopolymer composite films as packaging films useful in the food industry.
\end{abstract}

Keyword: Bamboo fiber; Biopolymer films; Biocomposite films 